\title{
PERFORMANCE PANEL SURYA SAAT GERHANA MATAHARI CINCIN PADA TANGGAL 26 DESEMBER 2019 DI KECAMATAN LARANGAN KABUPATEN BREBES
}

\section{PERFORMANCE OF SOLAR PANELS DURING THE SOLAR ECLIPSE RING ON DECEMBER 26, 2019 IN KECAMATAN LARANGAN KABUPATEN BREBES}

\author{
Sudarmono $^{1}$, Joko Waluyo ${ }^{2}$, Wahyu Wilopo ${ }^{3}$ \\ 1.Program Studi Teknik Mesin, Politeknik Baja Tegal \\ 2.Departemen Teknik Mesin dan Industri, Fakultas Teknik, Universitas Gadjah Mada \\ 3.Departemen Geologi, Universitas Gadjah Mada
}

\section{Informasi Makalah}

Dikirim, 04 Maret 2021

Direvisi, 14 Juli 2021

Diterima, 24 Agustus 2021

\section{Kata Kunci:}

Gerhana cincin

Pelacak matahari

Sudut kemiringan PV $23^{\circ}$

\section{Keyword:}

Eclipse rings

Sun tracker

The angle of the PV $23^{\circ}$

\begin{abstract}
INTISARI
Penelitian ini bertujuan untuk mengetahui performance teknologi PV dengan menggunakan PV pelacak matahari pada saat terjadi gerhana cincin tanggal 26 Desember 2019. Penelitian dilakukan dengan memvariasikan PV bersih dan kotor menggunakan metode penyesuian posisi matahari dalam satu tahun. Panel surya yang digunakan berkapasitas 3 Watt dengan tegangan 6 Volt dan beban baterai lithium $4000 \mathrm{mAh}$, panel surya diletakkan menghadap arah selatan dengan sudut kemiringan $23^{\circ}$. Pada bulan Desember step pelacak matahari berubah setiap 3 jam sekali dengan sudut $45^{\circ}, 90^{\circ}$ dan $115^{\circ}$. Pengujian dimulai dari pukul 07:00 WIB samapai pukul 15:00 WIB, dari pengujian diperoleh hasil daya rata-rata yang diterima oleh pembangkit tenaga listrik surya sebesar 1,08 Watt, dengan tegangan sebesar 4,24 Volt, dan arus listrik sebesar 0,25 Amper, sedangkan pada kapasitas PV bersih $2108 \mathrm{mAh}$ menghasilkan daya rata-rata sebesar 0,83 Watt, 4,36 Volt, 0,19 Amper dan kapsitas PV kotor sebesar 1524 mAh.
\end{abstract}

\author{
Korespondensi Penulis: \\ Sudarmono \\ Program Studi Teknik Mesin \\ Politeknik Baja Tegal \\ JL. Raya Dukuhwaru Jl. Jatibarang-Slawai No.KM, RW.7, Keplik, Dukuhwaru, Tegal, Jawa Tengah 52451 \\ Email: sudarmono92@mail.ugm.ac.id
}




\section{PENDAHULUAN}

Salah satu kebutuhan energi yang tidak dapat dipisahkan dalam kehidupan manusia adalah energi listrik. Kebutuhan energi listrik akan selalu meningkat seiring bertambahnya penduduk dan pembangunan. Terbatasnya sumber energi baik yang bersumber dari fosil maupun non fosil mendorong manusia untuk mencari dan memanfatkan energi lain yang tidak akan habis dan ramah lingkungan, sumber energi tersebut adalah teknologi panel surya. Energi matahari merupakan energi yang dapat dikonversi menjadi energi listrik yaitu panel surya [14] [15]. Teknologi panel surya memanfaatkan energi radiasi matahari untuk selanjutnya dikonversikan menjadi energi listik [1], sebab matahari adalah sumber energi yang potensial untuk kebutuhan manusia, yang mana energi tersebut diperoleh dari panas yang merambat sampai ke permukaan bumi. [5]. Hal ini sangat didukung karena Indonesia merupakan negara yang terletak di garis khatulistiwa yang memiliki tingkat radiasi harian matahari rata-rata relatif tinggi yaitu $4,5 \mathrm{kWh} / \mathrm{m}^{2} / \mathrm{hari}$ [9], dengan demikian posisi matahari menjadi sangat berpengaruh terhadap performace yang akan dihasilkan oleh panel surya.

Hal ini diperkuat dengan permasalahan utama dari energi surya adalah ketidak stabilan daya yang dihasilkan panel surya karena sangat bergantung pada intensitas matahari yang diterima. Intensitas cahaya matahari yang diterima oleh panel surya dapat dimaksimalkan dengan cara memasang panel surya dengan sudut kemiringan yang tepat sehingga akan diperoleh daya keluaran yang maksimal. Pada penelitian ini telah dilakukan optimasi sudut kemiringan panel surya yang akan digunakan pada prototipe sistem penjejak matahari aktif. Optimasi dilakukan dengan mengambil sudut teta $(\theta)$ pada sumbu x negatif dengan menggunakan sudut $0^{0}, 30^{0}, 45^{\circ}$ dan $60^{\circ}$ [4]. Selain itu dari hasil penelitian yang dilakukan oleh Muhammad Suyanto.dkk dapat diketahui bahwa dalam proses pengisian baterai dari panel surya yang diisi secara maksimal, dari pukul 09:00 WIB sampai pukul 16:00 WIB menghasilkan rata-rata tegangan dan arus pada setiap jamnya sebesar 14,07 Volt dan 0,60 Amper, sedangakan daya untuk alat dapat bekerja dalam satu malam (12 jam) yang di perlukan untuk menyuplai beban lampu LED dan kawat elektrik adalah sebesar 89,58 Watt [3].

Pada tanggal 26 Desember 2019 terjadi gerhana matahari cincin [13] yang dimulai dari pukul 10.50 WIB dengan puncak gerhana terjadi pada pukul 12.45 WIB dan berakhir pada pukul 14.30 WIB, durasi gerhana matahari cinci yang teramati di daerah Brebes rata-rata adalah selama 3 jam 30 menit dengan magnitudo gerhana matahari secara umum 0,7. oleh karenanya fenomena tersebut menyebabkan cahaya matahari tidak dapat sampai ke bumi secara penuh[2] sehingga mengakibatkan intenstitas matahari yang diterima oleh panel surya juga berubah. Berkaitan dengan hal tersebut, maka penelitian ini bertujuan untuk mengetahui perfomance panel surya pada saat terjadi gerhana matahari cincin tanggal 26 Desember 2019 dengan menggunakan panel surya bersih dan panel surya kotor.

\section{METODE}

Penelitian ini dilakukan di Kecamatan Larangan Kabupaten Brebes, metode pengumpulan data menggunakan tinjauan literatur dari buku dan jurnal mengenai sistem panel surya [6] dan bagaimana merangkai sebuah PV pelacak menggunakan arduino. Bahan dan alat yang digunakan meliputi : panel surya 3 watt dan 6 volt, baterai lithium 3,7 ukuran AA kapasiatas 4000 mAh, motor servo MG 9951800 dan arduino. Peralatan analisis yang digunakan yaitu USB tester volt meter dan satu unit laptop windows 764 bit untuk mengindentifikasi arus, volt, daya dan kapasitas pv (mAh) dari panel surya data tersebut nantinya diolah pada microsoft excel mengahasilkan data nilai rata-rata, nilai minimum dan nilai maksimum. Berikut ini adalah skema cara kerja solar tracker.

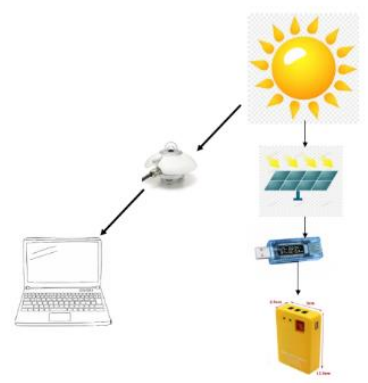

(Gambar 1. Skema Panel Surya)

Proses perancangan pembutan panel surya meliputi berbagai persiapan antara lain perancangan desain, pengumpulan komponen yang dibutuhkan [7]. Berikut ini adalah diagram alir perancangan panel surya untuk mempermudah pemahaman yang dilakukan dalam penelitian ini [16] [17], yaitu : 


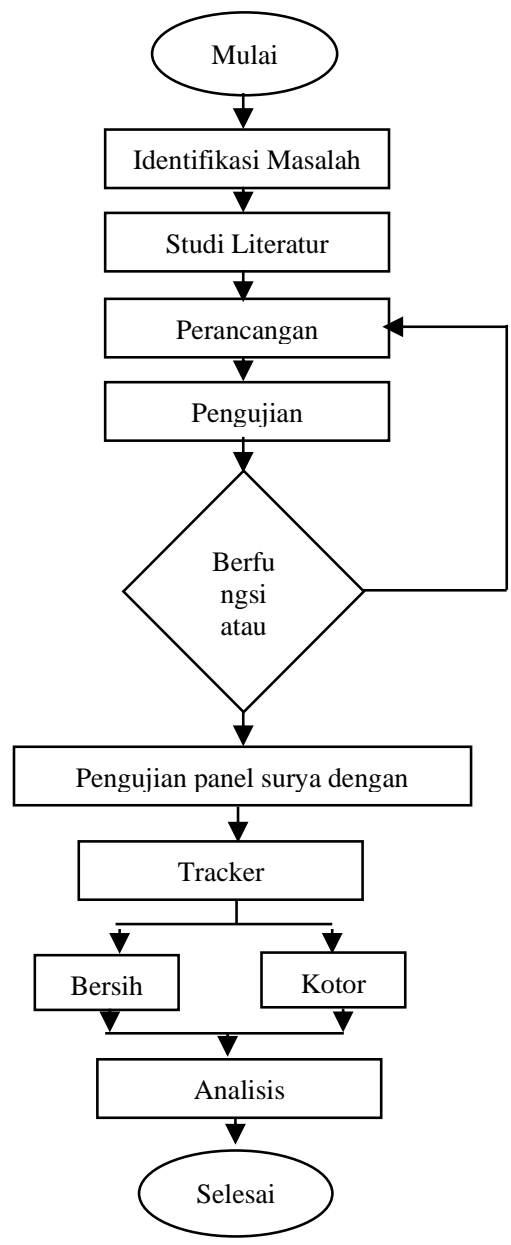

(Gambar 2. Diagram Alir)

Prosedur kerja diawali dengan dua buah panel surya yang bergerak mengikuti matahari, dengan menggunakan variasi sudut kemiringan panel surya, sudut yang digunakan dengan mengambil sudut kemiringan panel surya pada sumbu $\mathrm{x}$ negatif yang bertujuan untuk mengetahui nilai sudut kemiringan yang maksimal [8]. Selanjutnya arah panel surya yang optimal ada di selatan dengan sudut kemiringan $23^{\circ}$ dari posisi jalur matahari dalam satu tahun, kemudian memvariasikan bersih dan kotor yang sudah dikontrol setiap 3 jam sekali agar dapat bergerak $45^{\circ}, 90^{\circ}$ dan $115^{\circ}$ dan setiap satu jam output panel surya dipantau dan dicatat volt, arus, daya dan output kapasitas panel surya (mAh) yang dihasilkan oleh panel surya dari pukul 07:00 WIB samapai 15:00 WIB. Alat yang digunakan untuk mengukur radiasi matahari menggunakan pyranometer adalah salah satu jenis aktinometer yang digunakan mengukur radiasi matahari pada bidang datar. Pyranometer memiliki sensor yang dapat mengukur intensitas fluks radiasi matahari dalam satuan permeter persegi $(\mathrm{W} / \mathrm{m} 2)$ [1].

\section{HASIL DAN PEMBAHASAN}

Penelitian ini dilakukan dengan menggunakan dua buah panel surya dengan daya 3 watt dan tegangan 6 volt, dimensi yang digunakan yaitu panjang $22 \mathrm{~cm}$ dan lebar 13,5 cm dengan menggunakan satu panel bersih dan kotor yang masih mengikuti arah matahari. Panel surya bersih adalah panel surya yang pada saat pengujiannya tidak dilapisi plastik mika F4, sedangkan panel kotor adalah panel surya yang pada saat pengujiannya dilapisi plastik mika F4 yang dilipat menjadi dua bagian plastik mika. Pengujian ini dilakukan dalam satu hari dengan kondisi cuaca cerah dan terjadi gerhana matahari cincin yang dimulai dari pukul 07:00 WIB - 15:00 WIB. Gerhana matahari terjadi dimulai dari pukul 10.50 WIB dengan puncak gerhana terjadi pada pukul 12.45 WIB dan berakhir pada pukul 14.30 WIB, durasi gerhana matahari cincin yang teramati di daerah Brebes rata-rata adalah selama 3 jam 30 menit. Dari pengujian yang dilakukan dengan menganalisa perubahan arus, tegangan dan output panel surya dalam (mAh) pengisian dari panel surya ke baterai lithium 3,7 volt menggunakan proses charging berupa constant voltage didapat hasil sebagai berikut: 
Tabel 1. Hasil Pengujian Panel Surya Bersih

\begin{tabular}{|c|c|c|c|c|c|c|c|}
\hline \multirow[t]{2}{*}{ No } & \multirow[t]{2}{*}{ Waktu (WIB) } & \multirow{2}{*}{$\begin{array}{c}\text { Sudut } \\
\left({ }^{0}\right)\end{array}$} & \multirow{2}{*}{$\begin{array}{l}\text { Irradiance } \\
\left(\mathrm{w} / \mathrm{m}^{2}\right)\end{array}$} & \multicolumn{3}{|c|}{ Panel Surya Tracker Bersih } & \multirow{2}{*}{$\begin{array}{c}\text { Output } \\
\text { mAh }\end{array}$} \\
\hline & & & & V (Volt) & I (Ampere) & $\mathrm{P}$ (Watt) & \\
\hline 1 & 08:00 & 45 & 389,4 & 4,18 & 0,29 & 1,21 & 226 \\
\hline 2 & 09:00 & 45 & 484,4 & 4,34 & 0,29 & 1,26 & 455 \\
\hline 3 & $10: 00$ & 45 & 708,1 & 4,59 & 0,52 & 2,39 & 834 \\
\hline 4 & $11: 00$ & 90 & 865,6 & 4,42 & 0,23 & 1,02 & 1241 \\
\hline 5 & $12: 00$ & 90 & 488,1 & 4,53 & 0,35 & 1,59 & 1591 \\
\hline 6 & $13: 00$ & 90 & 198,1 & 4,09 & 0,05 & 0,20 & 1776 \\
\hline 7 & $14: 00$ & 115 & 500,6 & 4,38 & 0,20 & 0,88 & 1897 \\
\hline 8 & $15: 00$ & 115 & 286,9 & 4,36 & 0,14 & 0,61 & 2108 \\
\hline
\end{tabular}

Sumber : Pengujian 26 Desember 2019.

Tabel 2. Hasil Pengujian Panel Surya Kotor

\begin{tabular}{|c|c|c|c|c|c|c|c|}
\hline \multirow[t]{2}{*}{ No } & \multirow[t]{2}{*}{ Waktu (WIB) } & \multirow{2}{*}{$\begin{array}{l}\text { Sudut } \\
\left({ }^{0}\right)\end{array}$} & \multirow{2}{*}{$\begin{array}{l}\text { Irradiance } \\
\left(\mathrm{w} / \mathrm{m}^{2}\right)\end{array}$} & \multicolumn{3}{|c|}{ Panel Surya Tracker Bersih } & \multirow{2}{*}{$\begin{array}{c}\text { Output } \\
\text { mAh }\end{array}$} \\
\hline & & & & $\bar{V}$ (Volt) & I (Ampere) & $P($ Watt $)$ & \\
\hline 1 & 08:00 & 45 & 389,4 & 4,11 & 0,17 & 0,70 & 128 \\
\hline 2 & 09:00 & 45 & 484,4 & 4,18 & 0,20 & 0,84 & 286 \\
\hline 3 & 10:00 & 45 & 708,1 & 4,44 & 0,41 & 1,82 & 579 \\
\hline 4 & $11: 00$ & 90 & 865,6 & 4,18 & 0,17 & 0,71 & 890 \\
\hline 5 & $12: 00$ & 90 & 488,1 & 4,41 & 0,28 & 1,23 & 1165 \\
\hline 6 & $13: 00$ & 90 & 198,1 & 4,07 & 0,02 & 0,08 & 1295 \\
\hline 7 & $14: 00$ & 115 & 500,6 & 4,28 & 0,14 & 0,60 & 1378 \\
\hline 8 & $15: 00$ & 115 & 286,9 & 4,26 & 0,05 & 0,21 & 2539 \\
\hline
\end{tabular}

Sumber : Pengujian 26 Desember 2019

Menghitung daya yang dihasilkan oleh panel surya dapat dihitung dengan persamaan sebagai berikut

$\mathrm{P}=$ Volt $\times$ Ampere

$\mathrm{P}=4,11$ Volt $\times 0,29$ Ampere

$\mathrm{P}=1,19$ Volt

Dari hasil penelitian maka menghasilkan beberapa grafik sebagai berikut

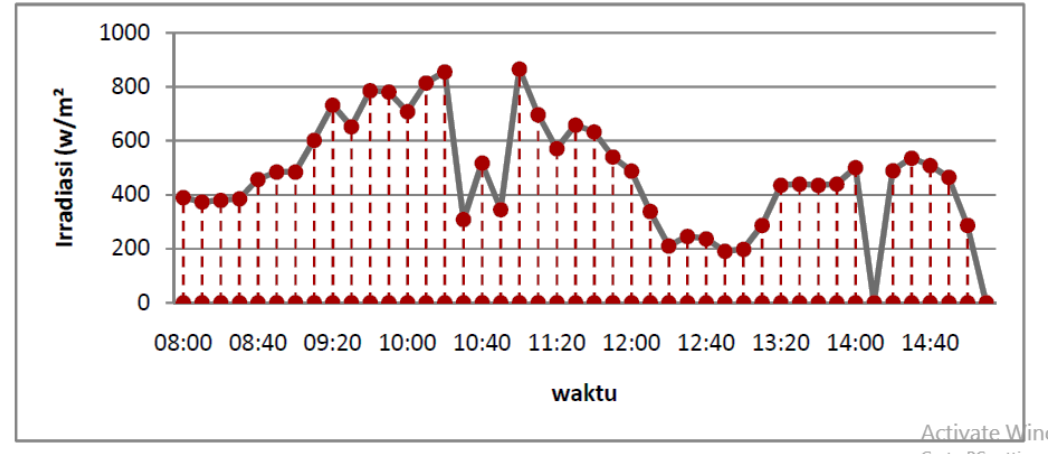

Gambar 3. Grafik Hasil Irradiasi Matahari dari Pyranometer

Gambar 3 adalah grafik hasil irradiasi matahari menggunakan pyranometer yang sudah terseting di program dalam 10 menit untuk pengambilan data, waktu penelitian pukul 07:00 sampai dengan 15:00 WIB, diketahui nilai minimum irradiasi matahari dari pyranometer $0,6 \mathrm{~W} / \mathrm{m} 2$ pada pukul 14:10 WIB sedangkan irradiasi matahari maksimum yang di dapat dari pyranometer 865,6 W/m2 pukul 11:00 WIB. 


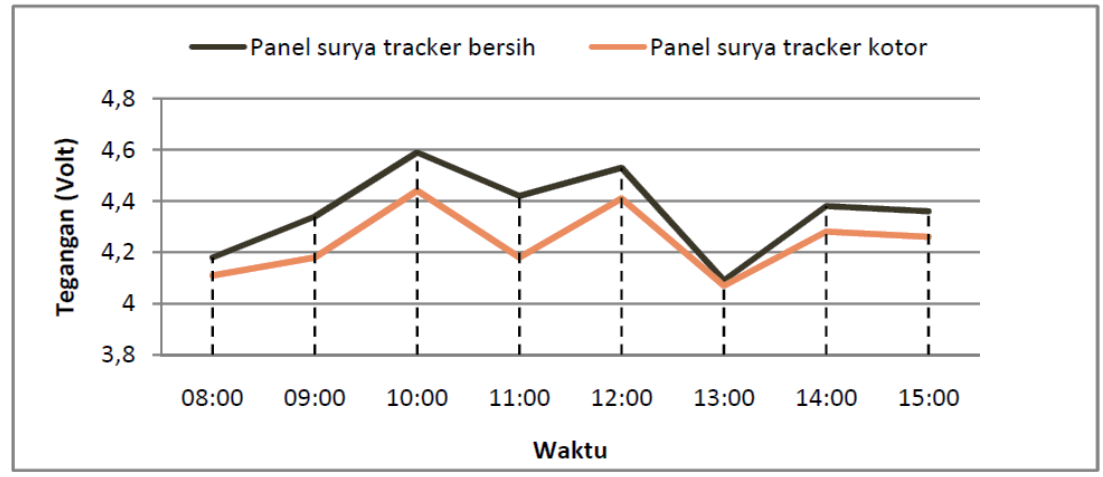

Gambar 4. Grafik Pengujian V (Volt) 26 Desember 2019

Dari gambar 4 menunjukkan bahwa nilai minimum tegangan setiap jamnya dari panel surya tracker bersih adalah 4, 09 Volt pada pukul 13:00 WIB dan nilai maksimum adalah 4, 59 Volt pada pukul 10;00 WIB, sedangkan nilai minimum dari pane surya tracker kotor adalah 4,07 pada pukul 13:00 WIB dengan nilai maksimum 4,44 pada pukul 10:00 WIB, jadi dapat disimpulkan bahwa tegangan panel surya tracker bersih selalu lebih efektif dibandingkan panel surya tracker kotor.

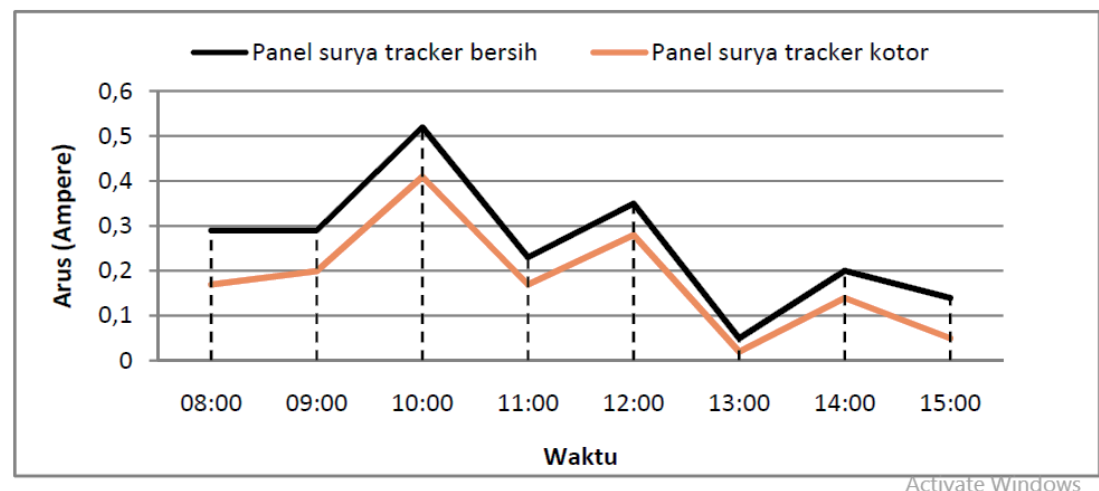

Gambar 5. Grafik Pengujian I (Ampere) 26 Desember 2019

Dari gambar 5 menunjukkan bahwa nilai minimum arus setiap jamnya dari panel surya tracker bersih adalah 0,05 ampere pada pukul 13:00 WIB dan nilai maksimum adalah 0,52 ampere pada pukul 10:00 WIB, sedangkan nilai minnimum tracker kotor adalah 0,02 ampere pada pukul 13:00 WIB dengan nilai maksimum 0,41 ampere pada pukul 10:00 WIB, jadi dapat disimpulkan panel surya tracker bersih lebih efektif dibandingkan panel surya tracker kotor.

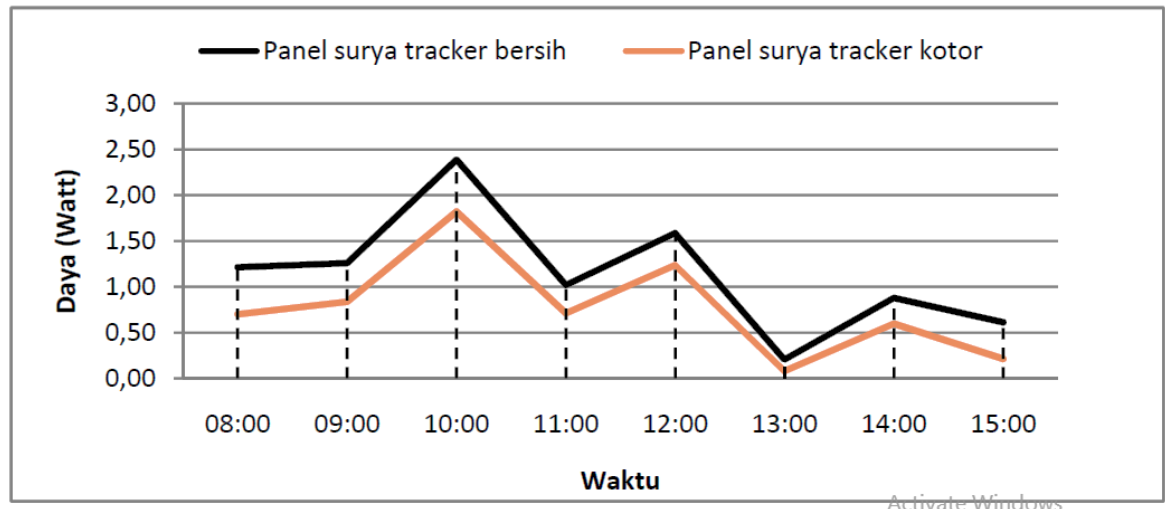

Gambar 6. Grafik Pengujian P (Watt) 26 Desember 2019

Gambar 6 menunjukkan bahwa nilai minnimum daya pada setiap jamnya dari panel surya tracker bersih adalah 0, 20 watt pada pukul 13:00 WIB dan nilai maksimum panel surya trcker bersih adalah 2,39 watt pada pukul 10:00 WIB, sedangkan nilai minimum panel surya tracker kotor adalah 0,08 watt pada pukul 13:00 
WIB dengan nilai maksimum 1,82 watt pada pukul 10:00 WIB, jadi dapat disimpulkan bahwa panel surya tracker bersih lebih efektif dibandingkan panel surya tracker kotor.

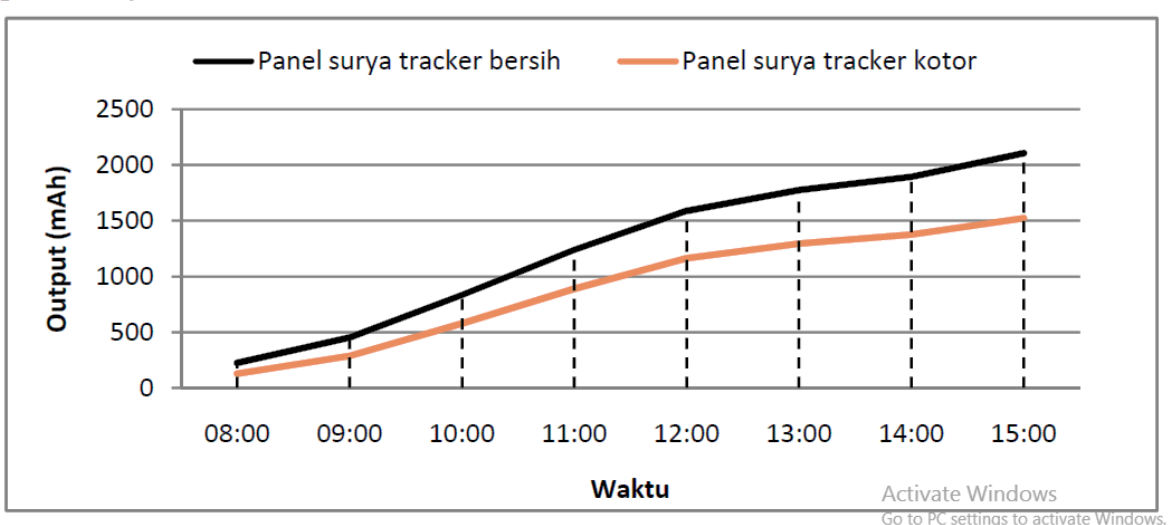

Gambar 7. Grafik Pengujian Output Panel Surya (mAh) 26 Desember 2019

Gambar 7. menunjukkan bahwa nilai minimum output panael surya tracker bersih setiap jamnya adalah 226 mAh pada pukul 08:00 WIB dan nilai maksimum output panel surya tracker bersih adalah 2018 mAh pada pukul 15:00 WIB, sedangkan nilai minimum output panel surya tracker kotor adlah 128 mAh pada pukul 08:00 WIB dan nilai maksimum output panel surya tracker kotor adalah 1524 mAh pada pukul 15:00 WIB, jadi dapat disimpulkan bahwa output panel surya tracker bersih lebih efektif dibandingkan output panel surya tracker kotor.

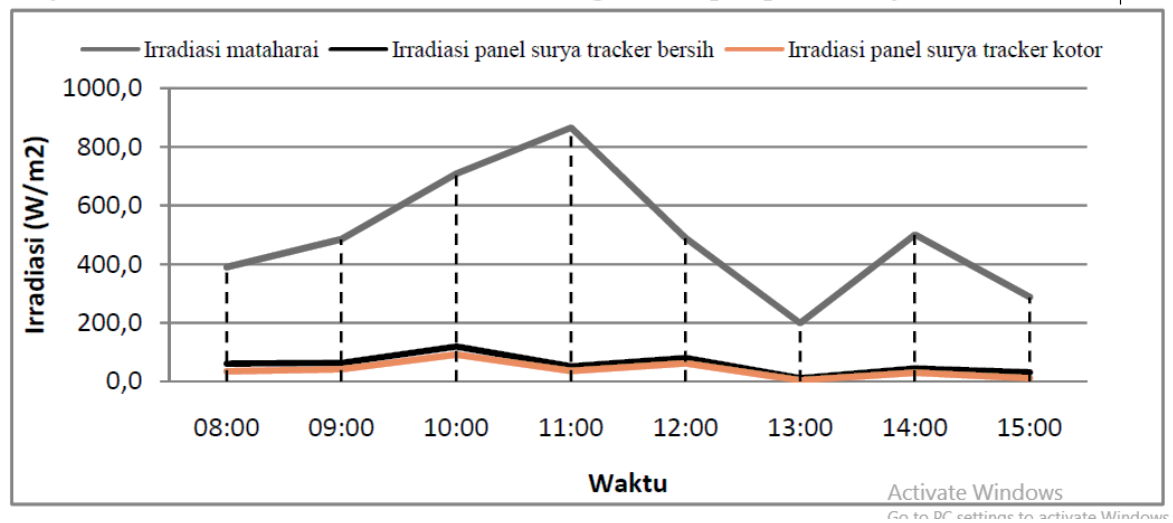

Gambar 8. Pengujian Irradiasi Pyranometer dan Panel Surya

Gambar 8 menunjukkan bahwa nilai minimum irradiasi matahari dari pyranometer dalam pengambilannya setiap jamnya adalah $198,1 \mathrm{watt} / \mathrm{m} 2$ pada pukul 13:00 WIB dengan nilai maksimum adalah $856,6 \mathrm{watt} / \mathrm{m} 2$ pada pukul 11:00 WIB, sedangkan nilai minimum irradiasi dari panel surya tracker bersih adalah 10,23 watt/m2 pada pukul 13:00 WIB dan nilai maksimum panel surya tracker bersih adalah 119,34 watt/m2 pada pukul 10:00 WIB dan nilai minimum iradiasi panel surya tracker kotor adalah 4,07 watt/m2 pada pukul 13:00 WIB dan nilai maksimum 91,02 pada pukul 10:00 WIB, dapat disimpulkan bahwa nilai panel sruya tracker bersih lebih efektif di bandingkan panel surya tracker kotor dalam menangkap irradiasi matahari.

$\mathrm{Ir}=\mathrm{P} \frac{\mathrm{P}}{\mathrm{A}}$

$\mathrm{Ir}=\frac{0,7}{0,0}$

$=35,28 \mathrm{~W} / \mathrm{m} 2$. Panel surya tracker bersih

$\mathrm{Ir}=\frac{0,7}{0,0}$

$\mathrm{Ir}=34,94 \mathrm{~W} / \mathrm{m}^{2}$. Panel surya tracker kotor 


\section{KESIMPULAN}

Dari pengujian yang telah dilakukan maka dapat diketahui bahwa gerhana matahari cincin yang terjadi pada bulan Desember 2019 pada saat mencapai titik puncaknya memberikan efek pada pengujian panel surya yang bergerak mengikuti matahari, salah satunya adalah pada penyerapan panel surya tracker bersih dan kotor yang ternyata masih dapat menghasilkan arus, tegangan dan daya.

\section{UCAPAN TERIMAKASIH}

Ucapan terimakasih disampaikan kepada Ir. Joko waluyo, M.T., Ph.D dan Dr. Wahyu Wilopo S.T. M.Eng para pembimbing atas bantuan yang telah diberikan selama proses penelitian.

\section{DAFTAR PUSTAKA}

[1] Duffie Johan A, William A. Beckman, "Solar Enginering of Thermal Processes”. John Wiley \& Sons, Inc., Hoboken, New Jersey Published simultaneously in Canada, 2013.

[2] BMKG, "Gerhana Matahari Cincin 26 Desember 2019 | BMKG," BMKG |Badan Meteorologi, Klimatologi, dan Geofisika. [Daring]. Tersedia pada:?p=gerhana-matahari-cincin-26-desember-2019\&tag=press-release\&lang=ID. [Diakses: 28-Jan-2020].

[3] Suyanto Muhammad, Subandi dan Encep Imam Cademas, "Sistem Peralatan Perangkap Serangga Tanaman Padi Dengan Panel Surya Sebagai Catu Daya”, pp. 1-6.

[4] S. Tamimi, W. Indrasari, dan B. H. Iswanto, "Optimasi Sudut Kemiringan Panel Surya Pada Prototipe Sistem Penjejak Matahari Aktif,” dalam Prosiding Seminar Nasional Fisika, 2016. SNF 2016. UNJ, 2016, pp. 53 - 56.

[5] Yuliananda, S., Sarya, G., \& Hastijanti, R. R. (2015). Pengaruh perubahan intensitas matahari terhadap daya keluaran panel surya. JPM17: Jurnal Pengabdian Masyarakat, 1(02).

[6] Sukmajati, S., \& Hafidz, M. (2015). Perancangan dan Analisis Pembangkit Listrik Tenaga Surya Kapasitas 10 MW On Grid di Yogyakarta. Jurnal Energi \& Kelistrikan, Volum 7 No. 1, Halaman 49-63.

[7] Maysha, I., \& Trisno, B. (2013). Pemanfaatan Tenaga Surya Menggunakan Rancangan Panel Surya Berbasis Transistor 2N3055 dan Thermoelectric Cooler, Jurnal Electrans, Volum 12 No. 2, Halaman 89-96

[8] Tamimi, S., Indrasari, W., \& Iswanto, B. H. (2016). Optimasi Sudut Kemiringan Panel Surya pada Prototipe Sistem Penjejak Matahari Aktif. In Prosiding Seminar Nasional Fisika (E-Journal) Volum 5 pp. SNF2016-CIP).

[9] Pangestuningtyas, D. L., Hermawan, H., \& Karnoto, K. (2014). Analisis Pengaruh Sudut Kemiringan Panel Surya Terhadap Radiasi Matahari yang Diterima Oleh Panel Surya Tipe Larik Tetap. Jurnal Ilmiah Teknik Elektro, Volum 2. No. 4 Halaman 930-937.

[10] Bachtiar, Muhammad. (2006). Prosedur Perancangan Sistem Pembangkit Listrik Tenaga Surya untuk Perumahan (Solar Home System)", SMARTek, Vol.4 No.3. Hal 176-182.

[11] Subiakto, T., Al-Ghozali, H. K., \& Jumadi, J. (2020). Dampak fenomena gerhana matahari cincin terhadap perilaku data radiasi matahari hasil observasi Lapan Pasuruan (26 Desember 2019). Prosiding SNPBS (Seminar Nasional Pendidikan Biologi dan Saintek) Ke-5.

[12] Utomo, H. S., Hardianto, T., \& Kaloko, B. S. (2017). Optimalisasi Daya dan Energi Listrik pada Panel Surya Polikristal dengan Teknologi Scanning Reflektor. BERKALA SAINTEK, Vol.5.No. 1 Hal 45-49

[13] Purwoto, B. H., Jatmiko, J., Fadilah, M. A., \& Huda, I. F. (2018) Efisiensi Penggunaan Panel Surya sebagai Sumber Energi Alternatif. Jurnal Teknik Elektro. Vol.18 No. 1, Hal 10-14

[14] Gifson, A., Masbah., \& M, Priyo Pambudi (2020). Rancangan Sistem Pembangkit Listrik Tenaga Surya On Grid di Ecopark Ancol. TESLA. Vol. 22, No. 1, 23-33.

[15] Ramadhan, A. I., Diniardi, E., \& Mukti, S. H. (2016). Analisis Desain Sistem Pembangkit Listrik Tenaga Surya Kapasitas 50 WP. Jurnal Teknik, Vol 37 No. 2 Hal 59-63. 
